\section{Actualidades en alimentación complementaria}

Cuadros-Mendoza $\mathrm{CA}^{1}$, Vichido-Luna $\mathrm{MA}^{1}$, Montijo-Barrios $\mathrm{E}^{2}$, ZárateMondragón $\mathrm{F}^{2}$, Cadena-León $\mathrm{JF}^{2}$, Cervantes-Bustamante $\mathrm{R}^{3}$, Toro-Monjáraz $\mathrm{E}^{2}$, Ramírez-Mayans $\mathrm{JA}^{4}$

\section{Resumen}

La introducción de nuevos alimentos, alimentación complementaria, en niños, siempre ha sido motivo de controversia; muy seguramente este debate continuará, debido a las diferencias que existen en cada grupo étnico y culturas en la población mundial, lo que hace necesaria la reunión frecuente de los diferentes grupos internacionales dedicados al estudio y manejo de la nutrición en pediatría. Anteriormente, era del dominio médico considerar que la introducción de alimentos se hacía con base en la experiencia personal: "cada maestro tiene su librito".

El departamento de gastroenterología y nutrición pediátrica del Instituto Nacional de Pediatría, México, analizó las diferentes guías existentes que hacen referencia a este tema, y con base en las recomendaciones actuales que rigen esta práctica y la experiencia de los autores, se elaboró un documento consenso adaptado a las tradiciones y patrones de alimentación de nuestro país, y en general aplicable a toda Latinoamérica, con información útil para la práctica diaria en la consulta de pediatría.

En este documento se especifican las bases fisiológicas por las cuáles y el por qué se debe iniciar la introducción de nuevos alimentos a la dieta, así como la forma adecuada en la que la alimentación complementaria debe indicarse, según la edad del paciente, considerando las recomendaciones de las guías que actualmente rigen la nutrición de los niños.

PALABRAS CLAVE: alimentación complementaria, ablactación, crecimiento, desarrollo.

Acta Pediatr Mex. 2017 May;38(3):182-201.

\section{News in supplementary feeding.}

Cuadros-Mendoza $\mathrm{CA}^{1}$, Vichido-Luna $\mathrm{MA}^{1}$, Montijo-Barrios $\mathrm{E}^{2}$, ZárateMondragón $\mathrm{F}^{2}$, Cadena-León $\mathrm{JF}^{2}$, Cervantes-Bustamante $\mathrm{R}^{3}$, Toro-Monjáraz $\mathrm{E}^{2}$, Ramírez-Mayans $\mathrm{JA}^{4}$

\footnotetext{
Abstract

The introduction of new foods, or complementary feeding (weaning) in the diet of children has always been controversial, and most likely this debate will continue due to the differences in each ethnic
}

${ }^{1}$ Residente de gastroenterología y nutrición pediátrica.

${ }^{2}$ Adscrito al Servicio de gastroenterología y nutrición pediátrica.

${ }^{3}$ Jefe del Servicio de gastroenterología y nutrición pediátrica.

${ }^{4}$ Jefe del Departamento de gastroenterología y nutrición pediátrica.

Instituto Nacional de Pediatría, México.

Recibido: 29 de septiembre del 2016

Aceptado: 21 de marzo del 2017

Correspondencia

Carlos Augusto Cuadros-Mendoza carlos1717@hotmail.com

Este artículo debe citarse como Cuadros-Mendoza CA, Vichido-Luna MA, MontijoBarrios E, Zárate-Mondragón F, Cadena-León J, Cervantes-Bustamante $\mathrm{R}$ et al. Actualidades en alimentación complementaria. Acta Pediatr Mex. 2017;38(3):182-201. 
group and cultures in the world's population, so frequent meetings of different international groups dedicated to the study and management of pediatric nutrition is necessary. Previously, the introduction of complementary feeding was based on personal experience, "each master has its booklet". The team of pediatric gastroenterology and nutrition at the Instituto Nacional de Pediatría, Mexico City, has an analyzed the different guidelines of complementary feeding in children, to create a document with useful information for daily practice in pediatric consultation. This document describes the physiological basis to establish the introduction of complementary feeding, why new foods should be introduced in the diet and the proper way complementary feeding should be indicated acording to the patient's age, considering the recommendations of the guidelines currently governing nutrition in children.

KEYWORDS: complementary feeding; weaning; growth; development

\author{
${ }^{1}$ Residente de gastroenterología y nutrición \\ pediátrica. \\ ${ }^{2}$ Adscrito al Servicio de gastroenterología y \\ nutrición pediátrica. \\ ${ }^{3}$ Jefe del Servicio de gastroenterología y \\ nutrición pediátrica. \\ ${ }^{4}$ Jefe del Departamento de gastroenterolo- \\ gía y nutrición pediátrica.
}

Instituto Nacional de Pediatría, México.

Correspondence

Carlos Augusto Cuadros-Mendoza

carlos1717@hotmail.com

\section{INTRODUCCIÓN}

En el año 2001 la Organización Mundial de la Salud definió la alimentación complementaria como todo aquel alimento líquido o sólido diferente de la leche materna que se introduce en la dieta del niño, incluyendo las fórmulas lácteas infantiles. ${ }^{1}$ El objetivo fue preservar, favorecer, o ambas cosas, la lactancia con leche materna en los primeros meses de vida. Sin embargo, años más tarde, la Academia Americana de Pediatría ${ }^{2}$ y posteriormente la Sociedad Europea de Gastroenterología, Hepatología y Nutrición Pediátrica ${ }^{3}$ establecieron que la alimentación complementaria debe considerarse como la introducción de otros alimentos y líquidos diferentes a la leche materna y a las fórmulas lácteas infantiles, con el fin de llenar las brechas de energía y nutrientes, que éstas no son capaces de proporcionar. No hay que olvidar que la alimentación complementaria implica cambios metabólicos y endocrinos que influyen en la salud futura del niño: "alimentación complementaria, futuro del adulto".
A nivel internacional, se utilizan otros términos para referirse a la alimentación complementaria tales como: Beikost en alemán; Weaning en inglés. La palabra ablactación actualmente no es reconocida por el diccionario de la Real Academia Española. Etimológicamente proviene del latín "ablactātio", que significa destete, término que actualmente se encuentra en desuso, ya que este proceso no implica una supresión de la leche materna o de las fórmulas lácteas infantiles.

\section{¿POR QUÉ INICIAR LA ALIMENTACIÓN COMPLEMENTARIA?, ¿CUÁL ES SU FINALIDAD?}

El niño durante su etapa de crecimiento y desarrollo adquiere y desenvuelve un sin número de habilidades, al mismo tiempo que incrementan sus requerimientos energéticos y nutricionales, por lo que la alimentación exclusiva con leche humana o artificial no puede ser igual en estas etapas de la edad pediátrica. Entre los objetivos que se persiguen con la introducción de la alimentación complementaria están: ${ }^{4}$ 
1. Promover un adecuado crecimiento y desarrollo neurológico, cognitivo, del tracto digestivo y el sistema neuromuscular.

2. Proveer nutrientes que son insuficientes en la leche materna, tales como: hierro, zinc, selenio, vitamina D.

3. Enseñar al niño a distinguir sabores, colores, texturas y temperaturas diferentes, así como a fomentar la aceptación de nuevos alimentos.

4. Promover y desarrollar hábitos de alimentación saludable.

5. Favorecer el desarrollo psicosocial, y la interrelación correcta entre padres e hijos.

6. Conducir a la integración de la dieta familiar.

7. Promover una alimentación complementaria que permita prevenir factores de riesgo para alergias, obesidad, desnutrición, hipertensión arterial, síndrome metabólico, entre otras.

Las necesidades y requerimientos nutricionales cambian proporcionalmente de acuerdo al crecimiento del niño. De manera característica, a partir del sexto mes de vida el bebé necesita un mayor aporte energético y de algunos nutrimentos específicos, tales como: hierro, zinc, selenio, calcio y las vitaminas A y D. ${ }^{3,4}$ La leche materna exclusiva y las fórmulas lácteas infantiles son insuficientes para cubrir estos requerimientos en el lactante sano, los cuales se deben aportar a través de la alimentación complementaria. ${ }^{1}$ Si la alimentación del niño no se ajusta a los requerimientos adicionales de estos nutrimentos, su crecimiento y desarrollo puede verse afectado. La Figura 1 muestra el déficit de aporte energético de un niño alimentado exclusivamente con leche materna.

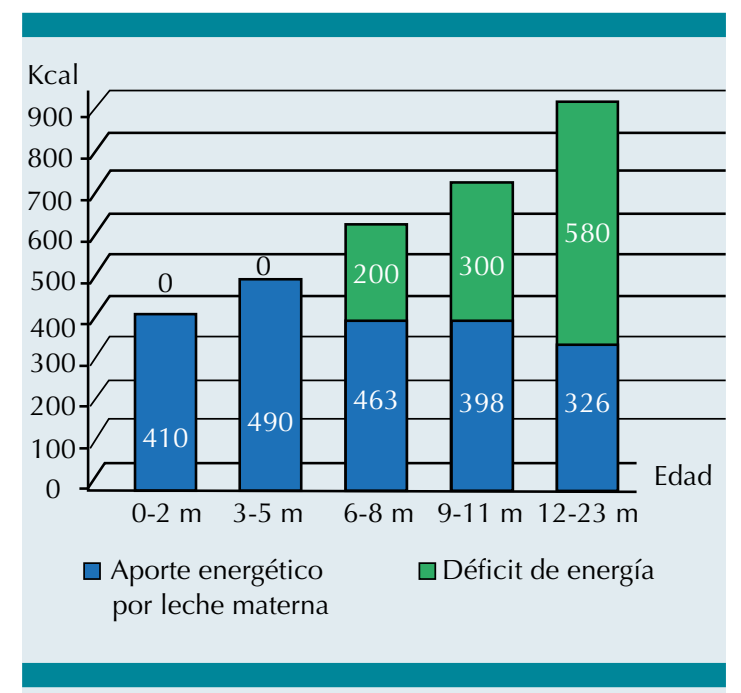

Figura 1. En la figura se muestran los requerimientos energéticos totales en niños de 0 a 23 meses de edad. En azul se ilustra el aporte energético que la leche materna ofrece según la edad. En verde se indica la cantidad de energía que debe ser cubierta con alimentos complementarios. ${ }^{1,4}$

\section{¿CUÁNDO INICIAR LA ALIMENTACIÓN COMPLEMENTARIA?}

Para iniciar la alimentación complementaria se deben tener en cuenta múltiples factores involucrados en el éxito de su buena implementación, tales como: la edad, la capacidad del niño para la digestión y absorción de los diferentes micro y macronutrientes presentes en la dieta, las habilidades sociales y motoras adquiridas, el medio socioeconómico en el que se encuentra y la incapacidad de la leche materna y de las fórmulas lácteas infantiles de asegurar un aporte energético adecuado de nutrimentos que garanticen el crecimiento y desarrollo adecuado del lactante. ${ }^{3-5}$

El proceso de nutrición implica la participación e interacción entre diferentes sistemas del cuerpo humano: digestivo, neurológico, renal e inmunológico, que desde la vida fetal se encuentran en constante desarrollo evolutivo. ${ }^{3-6}$ Es impor- 
tante conocer y reconocer estos procesos de evolución y adaptación con el fin de establecer recomendaciones para la introducción segura de diferentes alimentos de acuerdo al momento de maduración biológica del lactante, con el objetivo de no incurrir en acciones que sobrepasen su capacidad digestiva y metabólica., ${ }^{3,4}$

\section{Desarrollo neurológico}

En gran medida, la introducción de nuevos alimentos a la dieta se basa, en el desarrollo neurológico al momento de decidir iniciar la alimentación complementaria. Durante este proceso el lactante irá perdiendo reflejos primarios como el de extrusión de la lengua, que inicialmente lo protegían, al tiempo que gana capacidades necesarias para la alimentación de alimentos no líquidos como la leche materna y las fórmulas lácteas infantiles. ${ }^{6}$

Los lactantes menores de cuatro meses expulsan los alimentos con la lengua, "reflejo de protrusión"; sin embargo, después de esa edad pueden recibir y mantener los alimentos en la boca con mayor facilidad, debido a que han desaparecido los reflejos primarios de búsqueda y extrusión. ${ }^{6} \mathrm{~A}$ los seis meses, el lactante ha adquirido una serie de habilidades motoras que le permiten sentarse, al mismo tiempo que aparece la deglución voluntaria, que le permite recibir alimentos de texturas blandas: purés o papillas con cuchara. Transfiere objetos de una mano a otra, tiene sostén cefálico normal. ${ }^{6}$

Entre los siete y ocho meses se deben ir modificando gradualmente la consistencia de los alimentos, pasando de blandos a picados y trozos sólidos (Figura 2). A esta edad, el niño habitualmente ha adquirido la erupción de las primeras cuatro piezas dentarias (dos superiores y dos inferiores), ${ }^{7}$ ha mejorado la actividad rítmica de masticación, la fuerza y la eficacia con la que la mandíbula presiona y tritura los alimentos y deglute coordinadamente los alimentos sólidos triturados. Por estas razones, actualmente se recomienda no retrasar el inicio de esta práctica más allá de los 10 meses, incluso a pesar de que el niño no presente erupción dentaria, ya que se ha visto que a esta edad, el niño es capaz de masticar y triturar los alimentos sólidos con las encías, y el retraso en la introducción de este tipo de alimentos puede condicionar la presencia de alteraciones de la masticación en etapas posteriores. ${ }^{8}$

\section{El desarrollo del tracto gastrointestinal}

El protagonista principal de la nutrición en el niño sin duda es el tracto gastrointestinal, cuya maduración está íntimamente relacionada con la capacidad de introducir nuevos alimentos a la dieta. Alrededor de los cuatro meses de vida, el tracto gastrointestinal ya ha desarrollado los mecanismos funcionales, que le permiten metabolizar alimentos diferentes a la leche materna y las fórmulas lácteas infantiles., ${ }^{3,4}$ La capacidad del estómago del recién nacido a término es de $30 \mathrm{~mL}$; durante los seis meses siguientes su capacidad gástrica aumenta gradualmente, lo que le permite ingerir mayor cantidad de alimentos. ${ }^{9}$ De igual forma la motilidad gastrointestinal ha alcanzado un grado de maduración adecuado, mejorando el tono del esfínter esofágico inferior y la contractilidad antro-duodenal, lo que favorece un mejor vaciamiento gástrico, comparado con los meses previos. ${ }^{9} \mathrm{Al}$ mismo tiempo, aumenta la secreción de ácido clorhídrico, la producción de moco y se establece a plenitud la secreción de bilis, sales biliares y enzimas pancreáticas, facilitando la digestión y la absorción de almidones, cereales, grasas diferentes a las de la leche materna y proteínas. ${ }^{9-11}$ La Figura 3 muestra un esquema de la maduración y producción de enzimas necesarias para la digestión de los macronutrientes. ${ }^{10}$

En el periodo neonatal el intestino tiene un espacio mayor entre las uniones apretadas, como 


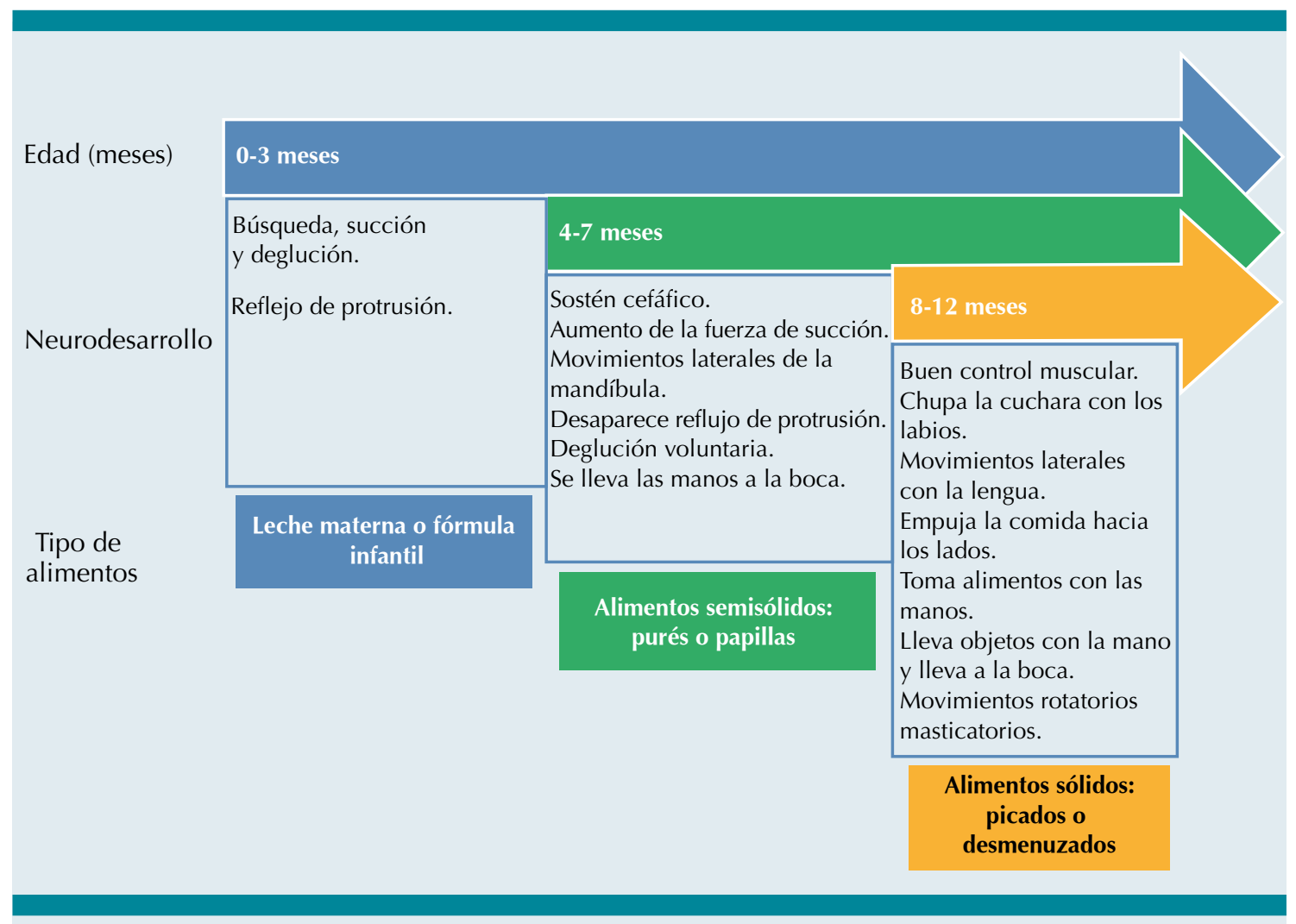

Figura 2. Esquema que relaciona la adquisición de los hitos del neurodesarrollo con el tipo de consistencia de los alimentos que un niño entre 0 y 12 meses es capaz de ingerir. ${ }^{1,4,5,7}$

esbozo de su antecedente funcional de la vida intrauterina. Conforme pasan los meses se va cerrando y mejoran su capacidad de "barrera mecánica", disminuyendo la entrada de alérgenos alimentarios. ${ }^{9}$

A partir de la exposición gradual del niño a diferentes tipos de alimentos, se promueven cambios a nivel de la microbiota intestinal, específicamente en las especies de bifidobacterias y lactobacilos, que impiden la colonización por microorganismo patógenos y al mismo tiempo participan en el desarrollo de tolerancia oral. ${ }^{12}$

\section{Función renal}

La importancia del estado de maduración renal radica en la capacidad que tendrá el lactante para depurar la cantidad de solutos presentes en los nuevos líquidos y alimentos introducidos en su dieta. La filtración glomerular del recién nacido es alrededor del $25 \%$ del valor del adulto, se duplican entre los dos y los tres meses de edad. A los seis meses el riñón alcanza cerca de $75-80 \%$ de la función del adulto, lo que le permite al lactante manejar una carga más alta de solutos. Por otra parte, alrededor de los seis meses de vida, la función renal ha alcanzado el grado de maduración necesario para manejar cargas osmolares mayores, lo que le permite tolerar un mayor aporte proteico y de solutos en la dieta. Antes de los seis meses la capacidad de concentración de la orina suele estar por debajo de 600-700 mOsm/kg. Al mismo tiempo los mecanismos de secreción y absorción tubular alcanzan un mayor grado de funcionalidad. ${ }^{13}$ 


\begin{tabular}{|c|c|c|c|c|c|c|c|c|c|c|c|}
\hline & \multicolumn{5}{|c|}{ Semanas de gestación } & \multirow[b]{2}{*}{ Nacimiento } & \multicolumn{5}{|c|}{ Meses de vida } \\
\hline & 10 & 20 & 25 & 30 & 35 & & 03 & 06 & 09 & 12 & 24 \\
\hline & \multicolumn{11}{|c|}{ Digestión de proteínas } \\
\hline Quimiotripsina & & & * & & & $10 \%$ & $60 \%$ & & & & \\
\hline Tripsina & & * & & & & $90 \%$ & & & & & \\
\hline Carboxypeptidasa & * & & & & & $10-20 \%$ & $60 \%$ & & & & \\
\hline \multirow[t]{2}{*}{ Enterocinasa } & & & * & & & $17 \%$ & & & & & \\
\hline & \multicolumn{11}{|c|}{ Digestión de líquidos } \\
\hline Lipasa pancreática & & & & * & & $10 \%$ & & & & $95 \%$ & \\
\hline Lipasa gástrica & & & * & & & $100 \%$ & & & & & \\
\hline \multirow[t]{2}{*}{ Bicarbonato } & * & & & & & & & & & & \\
\hline & \multicolumn{11}{|c|}{ Digestión de carbohidratos } \\
\hline Amilasa pancreática & * & & & & & & $* *$ & & & & \\
\hline Amilasa salival & & & * & & & $90-100 \%$ & & & & & \\
\hline Lactasa & & & & $30 \%$ & & $70 \%$ & & $100 \%$ & & & \\
\hline Sacarasa/maltasa & & & & $70 \%$ & & $100 \%$ & & & & & \\
\hline
\end{tabular}

Figura 3. Esquema que muestra en una línea del tiempo la producción y la capacidad funcional de las enzimas involucradas en la digestión de los macronutrientes durante la etapa prenatal, al nacimiento y los primeros 24 meses de vida. ${ }^{11}$ Se marca además el porcentaje de actividad al nacimiento, así como en otras edades. *Inicio de la producción. ** Inicio de la actividad de digestión de la amilasa pancreática.

¿QUÉ RECOMENDACIONES SE HAN PROPUESTO PARA UN ADECUADO INICIO DE LA ALIMENTACIÓN COMPLEMENTARIA?

\section{Edad de inicio}

El inicio de la alimentación complementaria está influido por una serie de factores anatómicos, fisiológicos ya mencionados, y otros no menos importantes que deben tenerse en cuenta en la práctica diaria, como la incorporación de la madre al trabajo, el tiempo disponible de los padres, el nivel adquisitivo familiar, la cultura de los padres, las costumbres propias de cada región y el ámbito rural o urbano. ${ }^{3}$ En Europa existe una amplia variación en la edad de introducción de alimentos complementarios: el 34\% de las madres en Italia introducen la alimentación complementaria antes de los cuatro meses $;{ }^{14}$ en Alemania el $16 \%$ a los tres meses; ${ }^{15}$ en el Reino Unido el $51 \%$ la han iniciado antes de los cuatro meses. ${ }^{16}$ Sin embargo, también hay registros de introducción tardía de la alimentación complementaria. Un estudio alemán mostró que alrededor del $20 \%$ de las madres alemanas pensaba que la lactancia materna exclusiva se debía continuar más allá de los seis meses. ${ }^{17}$

En México, la mediana de edad de inicio de alimentación complementaria fue cinco meses. Los primeros alimentos introducidos son cereales y legumbres, iniciados desde los dos meses hasta en el $4 \%$ de los casos. 5,18,19 De forma llamativa, la introducción temprana antes de los tres meses se observó con más 
frecuencia en las poblaciones urbanas, no indígenas y pertenecientes a mayores estratos socioeconómicos. ${ }^{18,20}$ Es probable que esta variabilidad entre países e incluso entre regiones dentro del mismo país, se deba a factores económicos y culturales.

La edad ideal para el inicio de la alimentación complementaria ha sido tema de interés y de controversia para los diferentes organismos que regulan el manejo nutricional en pediatría y han surgido diferentes opiniones al respecto. Desde 2001 la Organización Mundial de la Salud recomendó iniciar la alimentación complementaria a partir de los seis meses de vida, ya que la leche materna constituye un factor protector frente a la morbimortalidad infantil en los países en desarrollo. ${ }^{1,4,5}$ Las recomendaciones de la Sociedad Europea de Gastroenterología, Hepatología y Nutrición Pediátrica del 2008, señalan que el inicio de la alimentación complementaria no debe ser ni antes de las 17 semanas ni después de las 26 semanas de vida, tanto en los niños amamantados, como en los que reciben fórmulas lácteas infantiles o lactancia mixta. ${ }^{3}$ Con fines prácticos, el inicio de la alimentación complementaria puede recomendarse a partir, y no antes, de los cuatro meses en quienes estemos seguros de garantizar que los alimentos nuevos en la dieta satisfagan los requerimientos energéticos, y no debe diferirse más allá de los 6 meses en ningún paciente $^{5}$ (Figura 4).

\section{Continuación de la lactancia materna o fórmula láctea artificial durante la alimentación complementaria}

La lactancia materna debe acompañar la alimentación complementaria hasta los dos años de edad y debe ser administrada a demanda, debido a que durante este periodo sólo una parte de los requerimientos calóricos totales del niño son cubiertos por la alimentación complementaria. ${ }^{4,5}$ La lactancia materna puede aportar más

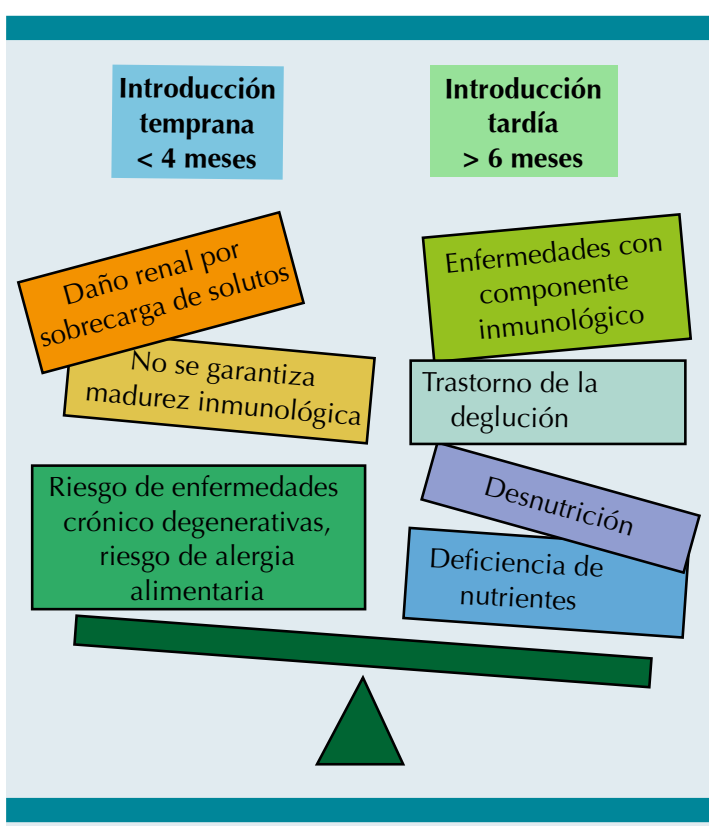

Figura 4. Esquema que detalla las complicaciones que pueden presentarse en un paciente con introducción temprana (antes de los 4 meses de edad), y tardía (después de los 6 meses de edad) de la alimentación complementaria. ${ }^{1,3,4}$

de la mitad de los requerimientos energéticos totales en un niño entre 6 y 12 meses de edad, y continua aportando nutrientes adecuados, junto con los alimentos complementarios; por lo tanto, el objetivo fundamental de la alimentación complementaria en esta etapa es poner en contacto y entrenar al niño con los alimentos que posteriormente lo van a acompañar a lo largo de su vida. Posteriormente, entre 12 y 24 meses de edad, la alimentación complementaria cubrirá más de la mitad de los requerimientos energéticos totales del niño; sin embargo, la lactancia materna continuará cubriendo hasta un tercio de los requerimientos de energía del niño, además de otros nutrientes de elevada calidad ${ }^{4}$ (Cuadro 1). Actualmente se recomienda a partir de los 12 meses un consumo máximo de $500 \mathrm{~mL}$ de leche materna o formula de crecimiento al día, equivalentes a 16 onzas, divididos en 2 tomas. ${ }^{3,5}$ 
Cuadro 1. Requerimientos energéticos de los 0 a los 24 meses de edad

\begin{tabular}{|l|c|c|c|c|c|}
\hline \multicolumn{1}{|c|}{ Edad } & $\mathbf{0 - 2}$ meses & $\mathbf{3 - 5}$ meses & $\mathbf{6 - 8}$ meses & $\begin{array}{c}\mathbf{9 - 1 1} \\
\text { meses }\end{array}$ & $\begin{array}{c}\mathbf{1 2 - 2 4} \\
\text { meses }\end{array}$ \\
\hline Requerimiento energía (kcal/día) & $400-670$ & $640-750$ & $700-774$ & $667-705$ & $580-894$ \\
\hline $\begin{array}{l}\text { Aporte energético cubierto por leche } \\
\text { materna o fórmula láctea infantil (kcal/día) }\end{array}$ & $400-670$ & $640-700$ & 463 & 398 & 326 \\
\hline $\begin{array}{l}\text { Producción de leche materna al día+ } \\
\text { e indicación de volumende leche } \\
\text { diario según la edad*y su aporte } \\
\text { energético }\end{array}$ & $\begin{array}{c}550 \mathrm{~mL} / \mathrm{día}^{+} \\
412 \mathrm{Kcal} / \mathrm{día}^{*}\end{array}$ & $\begin{array}{l}1150 \mathrm{~mL} / \mathrm{día}^{+} \\
862 \mathrm{kcal} / \mathrm{día}^{+}\end{array}$ & $\begin{array}{l}500 \mathrm{~mL} / \mathrm{día}^{*} \\
375 \mathrm{kcal} / \mathrm{día}\end{array}$ & $\begin{array}{l}500 \mathrm{~mL} / \text { día* }^{*} \\
375 \mathrm{kcal} / \mathrm{día}^{*}\end{array}$ & $\begin{array}{c}500 \mathrm{~mL} / \mathrm{día}^{*} \\
375 \mathrm{kcal} / \mathrm{día}^{*}\end{array}$ \\
\hline $\begin{array}{l}\text { Aporte energético cubierto por la } \\
\text { alimentación complementaria } \\
\text { (kcal/día) }\end{array}$ & 0 & 0 & 200 & 300 & 580 \\
\hline
\end{tabular}

En verde la energía otorgada por la leche materna o fórmulas lácteas infantiles, así como el volumen de leche por edad. ${ }^{1,3-5,7}$ En naranja se indica la cantidad de energía que deben ser cubierta con la alimentación complementaria. *Recomendaciones de la Organización Mundial de la Salud sobre el volumen de leche que requiere un niño entre 6 y 24 meses.

\section{Hábitos de alimentación}

La "alimentación perceptiva" se define como el comportamiento normal relacionado con los hábitos de alimentación. Este término es empleado para describir que el cuidador o cuidadora alimenta a los lactantes directamente y asiste a los niños mayores cuando comen por sí solos, respondiendo a sus signos de hambre y saciedad, alimentando despacio y pacientemente, animándolos a comer, pero sin forzarlos. Los padres deben tener presente que su obligación es ofrecer los alimentos, mientras el niño decide si los come o no y en qué cantidad. Cuando el niño rechaza el biberón, la cuchara, o escupe el alimento, es indicio que está satisfecho. ${ }^{4,5}$

De igual forma, se recomienda experimentar la introducción de alimentos con diversas combinaciones, sabores y texturas para animarlos a comer. La aceptación de algún alimento nuevo sólo se conoce después de al menos 3 a 5 intentos de ofrecérselo; si es rechazado nuevamente, se sugiere suspenderlo para ofrecerlo otra vez más adelante, igual o con otra presentación. ${ }^{5,7}$
El niño debe tener su propio plato, de manera que el cuidador pueda saber si el niño está recibiendo suficiente comida. Para alimentar al niño se puede emplear una cuchara, o las manos limpias; dependiendo de la cultura. El utensilio debe ser el apropiado para la edad del niño. ${ }^{4,5,7}$

Se deben reducir las distracciones durante las horas de comida y recordar a los padres que los momentos de comer son periodos de aprendizaje y amor, por lo que se debe hablar con los niños y mantener el contacto visual. ${ }^{4,5}$

\section{Preparación de alimentos e higiene}

La preparación y el almacenamiento seguros de los alimentos complementarios reducen el riesgo de diarrea. Por lo tanto, todos los utensilios, como vasos, tazas, platos y cucharas utilizados para alimentar al lactante, deben ser exhaustivamente lavados. En muchas culturas es común el comer con las manos, por lo que es importante que las manos del cuidador $y$ del niño sean cuidadosamente lavadas antes de comer. Se debe evitar el empleo de biberones debido al alto riesgo de transmisión de infec- 
ciones, por lo que se recomienda el empleo de vasos o tazas. ${ }^{4,5}$

Los alimentos deben ser debidamente refrigerados; cuando no puedan ser refrigerados, deben ser consumidos no más de 2 horas después de ser preparados, a fin de evitar que las bacterias tengan tiempo para multiplicarse. ${ }^{4,5}$

\section{Cantidad, textura y frecuencia de los alimentos}

A medida que el niño aumenta el consumo de alimentación complementaria, disminuye el consumo de leche materna, de manera que la alimentación complementaria desplaza la leche materna. Si se ofrecen alimentos de bajo valor nutricional que la leche materna (por ejemplo agua de panela o refrescos), la ingesta de energía será menor que la que obtenía con la lactancia materna exclusiva y esto puede causar desnutrición.

La cantidad verdadera de comida que requiere un niño depende de la densidad de los alimentos que se ofrecen y de la capacidad gástrica. En general, los alimentos de la alimentación complementaria tienen entre 0.6 y $1 \mathrm{kcal} / \mathrm{gramo}$, y en general es deseable que su densidad energética sea entre 0.8 y $1 \mathrm{kcal} /$ gramo. ${ }^{4,5}$

La consistencia más apropiada de la comida del lactante o niño pequeño, depende de la edad y del desarrollo neuromuscular. Al inicio de los seis meses, el lactante puede comer alimentos sólidos o semisólidos, en forma de puré o aplastados. A la edad de ocho meses, la mayoría de los lactantes puede comer alimentos sólidos triturados. A los 12 meses, la mayoría de los niños pueden comer los mismos alimentos consumidos por el resto de la familia (Figura 5). Existen pruebas sobre la presencia de una "ventana crítica" para incorporar alimentos triturados, de tal manera que si son administrados más allá de los 10 meses de edad, puede incrementar el riesgo posterior de sufrir problemas de alimentación, por lo que es importante elevar la consistencia de los alimentos de acuerdo a la capacidad que tiene el niño de ingerirlos. ${ }^{21}$

La cantidad de comida se incrementa de manera gradual, mes a mes, a medida que el niño crece y se desarrolla (Figura 5). Esta cantidad debe fraccionarse a lo largo del día, aumentando el número de comidas. ${ }^{4,5}$ La cantidad de comidas diarias que debe recibir el lactante dependerá de la energía que necesite para completar su requerimiento, de acuerdo a su capacidad gástrica y la densidad energética del alimento ofrecido.

Se recomienda iniciar la alimentación complementaria con una comida al día, que puede ser ofrecida por la mañana, o a la hora que convenga a la familia. Según el apetito del niño se incrementa el número a 2-3 comidas al día. Pueden ofrecerse colaciones o meriendas, procurando que sean nutritivas. , $^{4,7}$ Debe tenerse en cuenta que ofrecer al niño una baja cantidad de comidas al día, no cubrirá los requerimientos energéticos diarios. Por otra parte, el exceso de comidas diarias favorecerá el abandono precoz de la lactancia, incremento de peso y obesidad.

\section{Variedad de alimentos}

Un buen alimento complementario es rico en energía, proteínas y micronutrimentos (hierro, zinc, selenio, calcio, vitamina $\mathrm{A}$ y folatos); no es picante, dulce, ni salado; el niño puede comerlo con facilidad; es fresco, poco voluminoso e inocuo; debe ser de su agrado; está disponible localmente y es asequible. ${ }^{4,5}$

Los alimentos complementarios deberían brindar suficiente energía, proteína, lípidos, carbohidratos y micronutrientes para cubrir las brechas de energía que deja la leche materna. ${ }^{3,4}$ 
La alimentación complementaria debe basarse en alimentos que consume la familia, que dependerán de factores culturales y económicos. La dieta del niño debe tener alimentos básicos, ricos en determinados nutrientes (Figura 5) como:

\section{Cereales sin gluten}

Los cereales constituyen el grupo de alimentos con el que más se inicia la alimentación complementaria. ${ }^{3,4,7}$ Los cereales sin gluten aportan

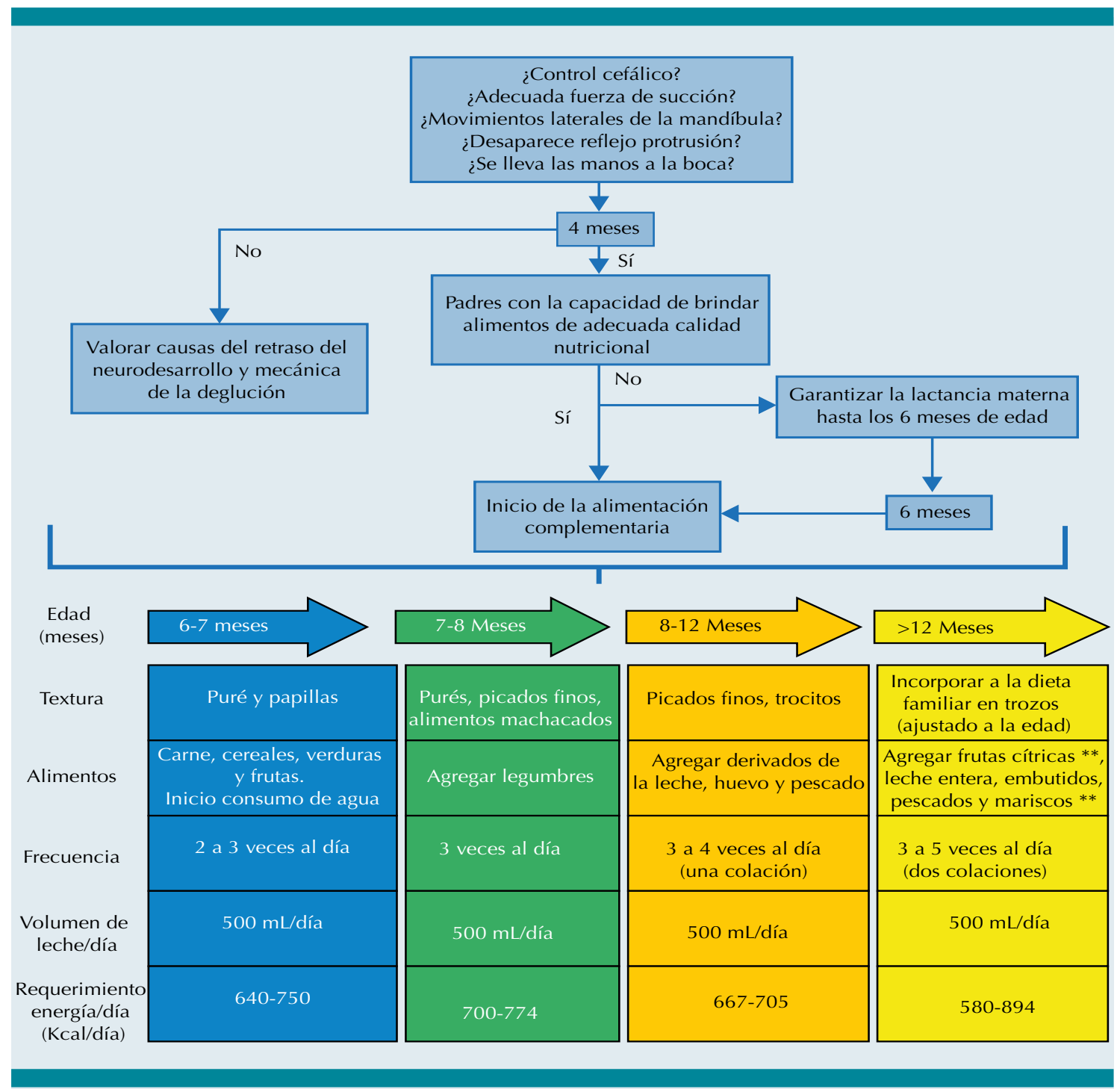

Figura 5. Si existen las condiciones adecuadas se debe iniciar la alimentación complementaria a los cuatro meses de edad, y nunca más allá de los 6 meses. Se recomienda iniciar con la introducción de un alimento nuevo cada 2 a 3 días, y en caso de que no acepta se debe intentar nuevamente en 7 días (realizar por lo menos 5 intentos). . $^{1,-5,7}$

** Evidencia reciente sugiere que no se deben retrasar los alimentos alergénicos, sin embargo en la actualidad no se ha llegado a un consenso en esta medida y se sugiere en guías actuales el retraso en caso familiares con alérgicos a dicho alimento. 
principalmente carbohidratos (almidón y polisacáridos), además de vitaminas, minerales y ácidos grasos esenciales, y están suplementados con hierro. Son preparados hidrolizados a base de arroz, maíz o soya, que pueden diluirse de forma instantánea, sin necesidad de cocción, tanto en la leche materna, como en las fórmulas lácteas infantiles, manteniendo un aporte lácteo adecuado. En algunos casos, y si hay rechazo por parte del niño, se pueden añadir a la papilla frutas o al puré de verduras o caldos.

\section{Cereales con gluten}

Los cereales con gluten están hechos con trigo, avena, cebada o centeno. Aportan hidratos de carbono, proteínas en menor cantidad, minerales, vitaminas y ácidos grasos esenciales. Constituyen un notable aporte de energía en función de su alto contenido de carbohidratos. De manera similar a los cereales sin gluten, han sido sometidos a un proceso de hidrólisis y están enriquecidos con hierro. Se preparan igualmente de forma instantánea diluyéndolos en leche materna o en la fórmula láctea infantil. No es preciso que los cereales sean siempre hidrolizados. Se pueden ofrecer también otros alimentos que aportan cereales, como arroz, avena, galletas, pan, pasta, etc. ${ }^{22}$

Actualmente, no existe un consenso sobre el mejor momento para introducir el gluten en la alimentación complementaria. ${ }^{23}$ Una medida prudente para la introducción del gluten sería hacerlo no antes de los 4 meses, ni después de los 7 meses de vida; independientemente de que el niño tome leche materna o una fórmula láctea infantil.

\section{Frutas y verduras}

En cada país existe una gran variedad de frutas y verduras que pueden integrar la alimentación complementaria. Las frutas aportan agua, hidra- tos de carbono, fibra, vitaminas y minerales. Las de color naranja son ricas en caroteno, precursor de vitamina A y en vitamina C. Deben prepararse peladas para evitar o limitar el aporte de celulosa y hemicelulosa presentes en la cubierta externa y así no sobrepasar los $5 \mathrm{~g}$ /día de fibra alimentaria recomendados durante el primer año de vida, evitando que el exceso de fibra pueda interferir con la absorción de micronutrientes, como el hierro y el zinc. Deben ofrecerse maduras para una mejor digestibilidad, en forma de papilla o zumos naturales recién elaborados, habitualmente entre comidas. ${ }^{22}$

Los jugos de fruta contienen todos los nutrimentos, incluyendo vitamina $\mathrm{C}$, lo que favorece la biodisponibilidad del hierro presente en otros alimentos vegetales cuando se administran en una misma comida. ${ }^{7}$ Los jugos deben ofrecerse con cuchara, para evitar el riesgo de caries con el biberón, debido a su alto contenido de carbohidratos. ${ }^{7}$ Además, se deben dar en pequeñas cantidades (máximo 6 onzas al día), para impedir que reemplacen la ingesta de leche o que interfieran con la aceptación de otros alimentos de mayor valor nutritivo. ${ }^{3}$

En cuanto a las verduras, aportan agua, proteínas vegetales, celulosa, vitaminas y minerales. Se pueden dar frescas o cocidas al vapor o hervidas en poca cantidad de agua y durante menos de 10 minutos para minimizar las pérdidas de vitamina $\mathrm{C}$ y de minerales. Además, durante la cocción debe taparse el recipiente para evitar que aumente en el agua la concentración de nitritos. ${ }^{7,22}$ Las verduras se ofrecen en forma de puré, de textura gradualmente menos fina para estimular la masticación.7,22 Es recomendable evitar al principio las verduras que causan flatulencias (coliflor, repollo) y las que contienen sustancias sulfuradas (ajo, cebolla, espárragos) responsables de sabores fuertes, ya que pueden resultar desagradables para el niño. ${ }^{22}$ Algunas verduras como el betabel, espinacas o zanahorias en gran 
cantidad, tienen alto contenido en nitratos, por lo que pueden ocasionar metahemoglobinemia en lactantes pequeños, debido a una baja acidez gástrica que permite la proliferación de bacterias reductoras de nitratos en nitritos, así como a una disminución fisiológica de la enzima metahemoglobina reductasa. ${ }^{7}$ Por esta razón, es aconsejable ofrecerlas en pequeñas cantidades. En general, las frutas y verduras pueden comenzar a formar parte de la dieta, de manera progresiva, a partir de los 5-6 meses de vida., ${ }^{3,4}$

\section{Carnes}

Son fuente muy importante de proteínas de alto valor biológico (20 g de proteína/100 g de carne), aminoácidos y ácidos grasos esenciales, hierro, zinc y vitaminas, principalmente B12. ${ }^{22}$

Debido al riesgo de carencia de hierro en niños con leche materna exclusiva a partir de los 6 meses, se recomienda la introducción de carne (pollo, pavo, ternera, vaca, cordero y cerdo) desde el inicio de la alimentación complementaria, por su alto contenido y buena disponibilidad de

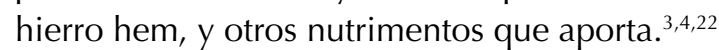
El valor nutritivo de la carne blanca es similar al de la carne roja. ${ }^{22}$ Se recomienda introducirla en cantidades pequeñas y progresivas, a diario, hasta llegar a 40-60 g de carne por ración al día; pueden ser añadidas al puré de verduras. ${ }^{22}$

\section{Derivados lácteos}

El yogur es un derivado lácteo fermentado que contiene poca lactosa, pero supone una excelente fuente de proteínas, calcio y vitaminas.,22 Además, favorece la absorción del calcio y regenera la flora intestinal gracias a su contenido de pre y probióticos. A partir de los 6 meses, se pueden introducir yogures elaborados con leche adaptada y, posteriormente, alrededor de los 9-10 meses, se pueden dar yogures naturales de leche de vaca entera. ${ }^{3,22}$
Los quesos son productos de leche fermentada que constituyen una buena fuente de proteínas, calcio, hierro y fósforo, pero pueden tener un alto contenido graso dependiendo del tipo de queso. Se pueden ofrecer quesos frescos poco grasos a partir de los 9-10 meses. ${ }^{3,22}$

\section{Pescado y huevo}

El pescado aporta proteínas de alto valor biológico, vitaminas, minerales como hierro, yodo, zinc, fósforo, sal y constituye una excelente fuente de ácidos grasos poliinsaturados de cadena larga omega 3 y 6 , presentes sobre todo en el pescado azul, de importancia en el neurodesarrollo y por su efecto beneficioso al aumentar el HDL-colesterol. ${ }^{22}$

Actualmente, se recomienda introducir el pescado a partir de los 9-10 meses, comenzando con pequeñas cantidades (unos 20-30 g) de pescado blanco o azul, siempre en cantidades pequeñas, que se irán aumentando paulatinamente hasta 40-60 g/día para favorecer la tolerancia. ${ }^{3,22}$ En niños menores de 3 años, deben evitarse algunos pescados, como el pez espada, atún rojo, tintorera y cazón, debido a su alto contenido de mercurio potencialmente perjudicial para el neurodesarrollo del niño. ${ }^{22}$

El huevo es considerado el alimento con mayor valor biológico en sus proteínas; aporta además ácidos grasos esenciales, (DHA-ARA) hierro, luteína y vitaminas. ${ }^{22}$ La yema se puede iniciar desde los 6 meses de edad, y posteriormente la clara de huevo cocida en cantidades crecientes, debido al alto poder alergénico de la ovoalbúmina que contiene. No es recomendable, por razones nutricionales y de seguridad alimentaria, consumir huevo crudo. Por una parte el calentamiento facilita la digestión completa de las proteínas del huevo; por otra, previene la deficiencia de biotina, vitamina pobremente absorbida cuando se consume huevo crudo, debido 
a que este contiene una proteína denominada avidina, que limita la absorción de la biotina. ${ }^{3,7,22}$ Además favorece la destrucción de posibles microorganismos contaminantes; se han reportado casos de infección por Salmonella gallinarum secundarios al consumo de huevo crudo en los que se ha encontrado contaminación de la yema de huevo por este microorganismo al romper el cascaron del huevo.?

\section{Legumbres}

Las legumbres aportan fibra, hidratos de carbono, proteínas, vitaminas y hierro, a pesar de que su biodisponibilidad es baja debido al elevado contenido en fibra y fitatos. ${ }^{22}$ Además, tienen un elevado contenido de nitratos, por lo que se recomienda iniciar en pequeñas cantidades para favorecer su digestión y evitar flatulencia, a partir de los 6-7 meses. ${ }^{7}$

\section{Agua}

La alimentación complementaria incluye un aumento de solutos y de carga osmolar importante, por lo que a los lactantes con fórmulas lácteas infantiles se les debe ofrecer pequeñas cantidades de agua hervida a lo largo del día, después de los 6 meses cuando el niño es capaz de sostener la composición de solutos que contiene. Los niños amamantados reciben líquidos suficientes, ya que la leche materna tiene un elevado contenido de agua (87\%) en su composición y, habitualmente, no necesitan suplementos de agua salvo en situaciones puntuales de calor excesivo o enfermedad febril. 3,22

\section{Alimentos no recomendados}

\section{Leche de vaca}

Se recomienda no introducir la leche de vaca entera hasta los 12 meses, por el riesgo de inducir anemia ferropénica debido a su bajo contenido en hierro y a su relación con micro sangrados intestinales y anemia. ${ }^{3,4,22}$ Además, teniendo en cuenta su alto contenido en proteínas, no se debe olvidar que son ácidos radicales y pueden ser causa de detención de crecimiento con base al fenómeno de strand (acidosis metabólica).

\section{Condimentos y edulcorantes}

No se debe añadir sal ni azúcar en la preparación de los alimentos para lactantes durante el primer año de vida, pues ambos componentes se encuentran en cantidades suficientes de forma natural en la dieta. Tampoco se deben dar edulcorantes porque refuerzan la preferencia innata por los sabores dulces y suponen un riesgo añadido de caries dentales y obesidad. ${ }^{7,22}$

\section{Miel de abeja natural}

La miel de abeja no procesada puede contener esporas de Clostridium botulinum, lo cual, sumado al déficit de ácido gástrico del lactante, facilitaría el desarrollo de botulismo. ${ }^{7}$

\section{Café, té, aguas aromáticas}

Hay que evitar las bebidas excitantes, como café, té o infusiones (específicamente a base de anís), ya que contienen alcaloides que producen cólico y además carecen de valor energético. ${ }^{\top}$ Las bebidas carbonatadas como los jugos artificiales, gaseosas y refrescos tampoco se recomiendan, porque disminuyen la absorción del calcio, proveen altas cantidades de energía, carecen de valor nutrimental pueden disminuir el apetito y la aceptación de otros nutrientes. ${ }^{7}$ El suministro de té interfiere con la absorción de hierro; por lo tanto, no se recomienda. Es conveniente evitar el uso de refrescos aparentemente con algún valor nutricional, lo cual no es cierto, pero es una costumbre cultural en nuestro país, ya que se da exceso de azúcar y favorece obesidad. 


\section{Alimentos con soya}

No se recomiendan los alimentos con soya porque su contenido de fitatos interfiere con la absorción del hierro y otros nutrimentos, además de favorecer el depósito de aluminio. ${ }^{7}$

\section{Embutidos}

No deben darse antes del año de edad por su elevado contenido de sodio, nitritos y grasas saturadas. ${ }^{7}$ Después del año se aconseja en cantidades mínimas supervisadas.

\section{Alimentos peligrosos}

Las nueces, cacahuates, maíz (palomitas de maíz), uvas pasas, entre otros, son alimentos peligrosos para los niños por debajo de los cuatro años de edad, debido a que el tamaño de estos condiciona riesgo de broncoaspiración y la probabilidad de que sean introducidos en las fosas nasales u oídos por curiosidad. ${ }^{3}$ Sin embargo, este tipo de alimentos pueden darse molidos o machacados y mezclarse con el resto de la dieta de forma segura.

\section{Suplementos de vitaminas y minerales}

Para los niños pequeños, los micronutrientes son esenciales para el crecimiento, el desarrollo y la prevención de enfermedades. En algunas situaciones la suplementación con micronutrientes puede ser una intervención efectiva. ${ }^{4,5}$

\section{Vitamina A}

La Organización Mundial de la Salud y el Fondo de las Naciones Unidas para la Infancia recomiendan la suplementación universal con vitamina A como una prioridad para niños de 6-59 meses de edad en países con un riesgo elevado de deficiencia. ${ }^{4}$ En estos países, se debe administrar una dosis elevada de vitamina $\mathrm{A}$ a los niños con sarampión, diarrea, enfermedad respiratoria, varicela, otras infecciones graves o desnutrición aguda grave. ${ }^{4}$ En la última actualización de la Organización Mundial de la Salud sobre este tópico, publicada en 2011, se recomienda administrar a niños entre 6 y 12 meses 100,000 UI en un oportunidad; y a niños mayores de 12 meses 200,000 UI cada 4-6 meses. $^{24}$

\section{Hierro}

La Academia Americana de Pediatría recomienda la suplementación con hierro a partir del cuarto mes, fecha en que aumentan los requerimientos de hierro por el crecimiento rápido. ${ }^{4}$ Sin embargo, en países como México debe suplementarse tan temprano como sea posible, a una edad de uno a dos meses. El hierro en la leche materna, aunque es escaso, tiene una elevada biodisponibilidad, por lo que cubre los requerimientos en los primeros 6 meses de vida. ${ }^{4}$ Actualmente, tanto las fórmulas infantiles como los cereales están suplementados con hierro, por lo que a partir de los 5-6 meses, en general, se logran aportes adecuados de hierro con la dieta, a través de la leche materna o fórmulas lácteas infantiles, los cereales fortificados $y$, especialmente, por la ingesta de carne y pescado. ${ }^{22}$ Sin embargo, el hierro en estas presentaciones tiene poca biodisponibilidad. Recientemente se publicaron las últimas recomendaciones de la Organización Mundial de la Salud al respecto, estableciendo que regiones donde la prevalencia de la anemia en los lactantes sea mayor del $40 \%$, y regiones que carezcan de datos de prevalencia en este grupo, considerando el alto riesgo de anemia, se recomienda administrar suplementos exógenos de hierro desde los 4 a los 23 meses (10-12,5 mg de hierro elemental/día), preferiblemente hierro aminoquelado dada su alta biodisponibilidad, absorción, etc. ${ }^{25}$

Es necesario tener cuidado con la suplementación con hierro en zonas donde la malaria es 
endémica, en las cuales no se recomienda la suplementación universal con hierro. En estas zonas, la prevención y el tratamiento de la anemia requiere un sistema de tamizado que permita la identificación de niños con deficiencia de hierro y de la accesibilidad a tratamiento antimalárico apropiado. Los suplementos con hierro no deben administrarse a niños que tengan suficientes reservas de este mineral ya que el riesgo de aparición de eventos adversos graves es mayor. ${ }^{26,27}$

Yodo

Grupos vulnerables como mujeres embarazadas o en período de lactancia y niños menores de 2 años podrían no estar cubiertos de manera adecuada en regiones, donde la estrategia de yodación de la sal, no está completamente ejecutada. En estos casos, la suplementación con yodo estaría indicada. ${ }^{28}$

Zinc

Se recomienda la suplementación con zinc a los recién nacidos pretérmino desde los dos meses hasta el año de vida, a razón de $3 \mathrm{mg} /$ día. En el caso de lactantes menores de 6 meses de edad, la dosis del zinc debe ser de $10 \mathrm{mg} /$ día. $^{29}$

\section{Vitamina D}

Tanto la Academia Americana de Pediatría, como diversas sociedades pediátricas internacionales y una revisión Cochrane (2008), recomiendan un suplemento diario de $400 \mathrm{UI}$ de vitamina $D$, durante el primer año de vida, a partir de los 15 días, tanto si el lactante recibe leche materna como si se alimenta con fórmulas lácteas infantiles con una ingesta menor de un litro de leche al día. ${ }^{30}$ No olvidar que es conveniente la exposición a la luz solar para establecer una mejor transformación de la vitamina D.

\section{ALIMENTACIÓN COMPLEMENTARIA, ¿¿FU- TURO DEL ADULTO?}

Enfermedad celíaca: hace algunos años se iniciaba el gluten a partir del sexto mes; sin embargo, durante la primer década de este siglo, se describieron algunos trabajos que definían el intervalo entre los 4 a 6 meses de vida, como un "periodo de ventana inmunológica", durante el cual, el desarrollo del sistema inmune favorecía la tolerancia de alimentos potencialmente alergénicos, como el gluten. ${ }^{31}$ Además se relacionó a la lactancia materna al momento y después de la introducción gradual del gluten, con un menor riesgo de enfermedad celíaca en niños que tenían predisposición genética de desarroIlarla; aunque no estaba claro si sólo retrasaba el comienzo de los síntomas o si confería una protección permanente frente a dicha enfermedad..$^{32}$ Fue con base en estos trabajos que la Sociedad Europea de Gastroenterología, Hepatología y Nutrición Pediátrica recomendố el inicio del gluten a partir de los 4 meses y antes de los 7 meses, en pequeñas cantidades y con aumentos graduales, en niños con riesgo genético de enfermedad celíaca, siempre acompañado de lactancia materna, debiendo continuarla después de la introducción del gluten. ${ }^{3}$ Sin embargo, un reciente estudio europeo multicéntrico constató que la introducción temprana de gluten entre los 4 y los 6 meses acompañada de lactancia materna, en niños genéticamente predispuestos, no reduce el riesgo de enfermedad celíaca. ${ }^{33}$ Otros trabajos han mostrado que retrasar el gluten hasta los 12 meses en niños con riesgo genético no reducen el riesgo de enfermedad celíaca, aunque sí retrasa su aparición, afectando menos el desarrollo del niño. ${ }^{34}$

Alergias: uno de los objetivos de la alimentación complementaria es evitar la presencia o el desarrollo de enfermedades alérgicas. Históricamente para ello se ha tratado de eliminar o retrasar la introducción de ciertos alimentos con alto potencial alergénico, como el huevo, el 
pescado, el cacahuate o las nueces. Hasta hace unos años, la Academia Americana de Pediatría recomendaba la introducción del huevo y de pescado después del año de edad en niños con riesgo de dermatitis atópica. ${ }^{35}$

En 2006 el Comité Americano de Alergia, Asma e Inmunología publicó un documento de consenso que recomendaba retrasar el inicio de la leche de vaca hasta la edad de un año; los huevos a los 2 años; las nueces, el pescado y los mariscos hasta los 3 años, en niños con alto riesgo de enfermedades alérgicas. ${ }^{36}$ Esta postura fue muy cuestionada y posteriormente modificada, ya que no se encontró evidencia científica suficiente que la apoyara..$^{34,37-39}$ Otros trabajos sugerían que retrasar la introducción de los alimentos con potencial alergénico, no sólo no reducía el riesgo de alergias, sino que podía aumentarlo. ${ }^{40}$ Por otra parte, existe evidencia de que la medida dietética más eficaz en niños con alto riesgo de enfermedad atópica, es la lactancia materna exclusiva hasta los 4 a 6 meses. Se ha encontrado que ésta disminuye la incidencia de dermatitis atópica, alergia a la proteína de la leche de vaca y asma. ${ }^{41}$

Sobre estas bases, la Sociedad Europea de Gastroenterología, Hepatología y Nutrición Pediátrica recomendó el inicio de la alimentación complementaria no antes de las 17 semanas; que los alimentos deberían añadirse de uno en uno para detectar las reacciones individuales y que no se debe evitar o retrasar la introducción de alimentos potencialmente alergénicos (huevo, pescado) en niños con o sin riesgo de enfermedad alérgica más allá de los 9 meses. ${ }^{3}$

Recientemente se publicó un trabajo en el Reino Unido que incluyó 640 lactantes, a los cuales se les realizó "prick test" (SPT); 542 pertenecieron al grupo con SPT negativo y 98 al grupo con SPT positivo. A los 60 meses de edad, de los pacientes del grupo con SPT negativo, $13.7 \%$ de la cohorte sin cacahuete y $1.9 \%$ de la cohorte de consumo desarrollaron alergia al cacahuete. Esto representa un $86.1 \%$ de reducción relativa en la prevalencia de alergia al cacahuete en pacientes que consumían este alimento. Por otra parte, de los 98 pacientes del grupo con SPT positivo, $35.3 \%$ de la cohorte sin cacahuate y el $10.6 \%$ de la cohorte de consumo desarrollaron alergia al cacahuete. Esto representa $70 \%$ de reducción relativa en la prevalencia de alergia al cacahuete en el grupo que lo consumió. Este estudio mostró que la introducción temprana de cacahuete en la dieta puede evitar el desarrollo de alergia al cacahuete en lactantes con alto riesgo de padecerla. ${ }^{42}$

Perkin y sus colaboradores publicaron este año una revisión sistemática de la literatura, en la cual no evidencian que el retraso de la introducción de alimentos potencialmente alergénicos, tenga efecto en el desarrollo de las enfermedades atópicas. ${ }^{43}$

Diabetes mellitus: el riesgo de desarrollar diabetes tipo 1, se ha encontrado asociado con la edad de introducción de los cereales. En el estudio DAISY la introducción de cereal antes de los 3 meses o por encima de los 7 en familiares de primer grado de diabéticos tipo 1 se asoció a un aumento en auto anticuerpos anti islote. Cuando los cereales se introdujeron mientras los niños estaban con leche materna, el riesgo disminuía ligeramente. ${ }^{44}$ No existen datos que muestren un efecto de la edad de introducción de la alimentación complementaria sobre el riesgo de desarrollar diabetes mellitus tipo 2 . Sólo existen informes que sugieren que la leche materna puede proporcionar cierto grado de protección a largo plazo contra el desarrollo de diabetes tipo $2 .{ }^{45}$

Obesidad: Existe información contradictoria entre la asociación de la edad de inicio de la alimentación complementaria y el riesgo de obesidad. Mientras muchos estudios no encuentran 
ninguna asociación, ${ }^{46}$ Pearce y sus colaboradores encontraron un riesgo aumentado cuando la alimentación complementaria se introduce antes de las 15 semanas. Por otra parte, un estudio australiano de seguimiento en 620 sujetos nacidos entre 1990 y 1994 encontró que la introducción tardía de la alimentación complementaria (6 meses o más) se asoció con menor riesgo de sobrepeso y obesidad a los 10 años. ${ }^{47}$ En general, la mayoría de estudios muestran un efecto protector de la leche materna frente al riesgo de obesidad posterior. ${ }^{48}$

\section{IMPLICACIONES FUTURAS Y NUEVAS FORMAS DE ALIMENTACIÓN COMPLE- MENTARIA}

¿Cómo debe ser la alimentación complementaria en hijos de padres vegetarianos?

En los niños menores de 2 años existe controversia acerca de si deben recibir o no dietas vegetarianas estrictas, por el insuficiente aporte de energía, y el riesgo de carencias nutricionales de vitaminas, principalmente de vitamina B12, riboflavina y vitamina $\mathrm{D}$, proteínas animales y minerales (hierro, zinc, calcio). Estas deficiencias pueden dar lugar a malnutrición proteico-calórica, raquitismo, anemia ferropénica, anemia megaloblástica y retraso del crecimiento y del desarrollo psicomotor en los lactantes, y se ven compensadas cuando la dieta incluye lácteos (lactovegetariana) o leche y huevos (ovolactovegetariana), ya que proporcionan proteínas de alto valor biológico, calcio y vitaminas $\mathrm{D}$ y del grupo B. Los lactantes amamantados por madres con dieta vegetariana estricta pueden requerir suplementos de vitaminas D y, especialmente, B12, hierro y calcio., ${ }^{3,4}, 49$

¿Alimentación complementaria dirigida por el bebé (Baby-led Weaning)?

El Baby-led weaning (BLW), es un término anglosajón que se traduce como "alimentación complementaria dirigida por el bebé". Esta práctica ha venido cobrando interés en algunos países en los últimos años, dándole difusión en foros en las redes sociales. El BLW es una forma de alimentación en la que el propio lactante, a partir de los 6 meses de vida y en función de su desarrollo neurológico, se lleva a la boca alimentos enteros, adaptados al bebé, utilizando sus manos, en lugar de recibirlos triturados y con cuchara. Al niño se le deja comer por sí solo teniendo un papel activo en decidir qué, cuánto y a qué ritmo comer. ${ }^{50,51}$

Entre de las ventajas descritas de esta forma de alimentación se mencionan que favorece la autonomía del niño, le permite participar de la comida familiar, estimula la masticación y disminuye el riesgo de sobrealimentación y de obesidad, ya que los bebés autorregulan las cantidades que ingieren. ${ }^{51}$ Sin embargo, esta práctica tiene ciertos riesgos y requiere un estrecho seguimiento del estado nutricional. Sus principales inconvenientes son: el riesgo de asfixia por atragantamiento, por lo cual incluso grupos que apoyan esta tendencia de alimentación brindan a los padres clases de primeros auxilios para estar prevenidos en este tipo de complicaciones. La posibilidad de que el niño tome menos variedad de alimentos es otra de las desventajas; así como que la cantidad de alimento sea insuficiente para un crecimiento adecuado, lo que puede traducirse en la aparición de algunas deficiencias nutricionales tales como el hierro, pudiendo condicionar anemia ferropénica o megaloblástica. Todas las deficiencias nutricionales expuestas anteriormente podrían llevar a un retraso de crecimiento. ${ }^{51}$

Posteriormente, Cameron y sus colaboradores realizaron un estudio, en el que plantearon una modificación del BLW, el "Baby-led Introduction to Solids" (BLISS), que se traduce como "introducción de sólidos dirigida por el bebé". Esta forma de autoalimentación propicia el con- 
sumo de alimentos ricos en hierro, energéticos y sin riesgo a atragantamiento. Esta práctica fue aceptada y aplicada por los padres, dando como resultados mayor consumo de alimentos ricos en hierro y menor riesgo de atragantamiento, al comparar este enfoque con el BLW. Sin embargo, vale la pena resaltar que pese a que el grupo BLISS ofreció mayor cantidad de carne roja (20.1 g/día) que el grupo BLW (3.2 g/día) $(P=0.014) 57$, no se encontraron diferencias estadísticamente significativas en la cantidad de hierro de los alimentos complementarios por el BLISS (4.9 mg/día) y BLW (2.2 mg/día). Esto probablemente debido a que el tamaño de la muestra era insuficiente para alcanzar un adecuado poder estadístico. ${ }^{52}$

\section{CONCLUSIONES}

Es probable que las prácticas de alimentación durante los primeros 24 meses de vida sean un factor determinante sobre la salud y el desarrollo de algunas enfermedades a corto, mediano y largo plazo. La investigación de estos efectos es un desafío clínico debido a la gran diversidad y complejidad de prácticas en alimentación durante este grupo etáreo, lo que puede limitar la viabilidad y generalización de los ensayos clínicos realizados sobre este tema. Los datos disponibles son limitados tanto en cantidad como en calidad, pero sugieren que los alimentos complementarios (es decir, los alimentos sólidos y líquidos distintos la leche materna o las fórmulas lácteas infantiles), no deben ser introducidos antes de los 4 meses, pero no deberían retrasarse más allá de 6 meses, ya que se ha visto que esta práctica podría impactar en la reducción del riesgo de alergia y obesidad a mediano y largo plazo.

A la luz de la evidencia actual se establecen las siguientes recomendaciones: la lactancia materna idealmente debería acompañar la introducción de la alimentación complementaria. La leche de vaca no debe ser utilizada antes de los 12 meses de edad, ya que carece de un adecuado aporte de hierro y proporciona proteínas, grasa, y calorías en exceso. Los alimentos alergénicos pueden introducirse desde los 4 meses (17 semanas) junto con otros alimentos complementarios. En niños con alto riesgo de alergia al cacahuate (aquellos con eczema severo, alergia al huevo, o ambos), este debe ser introducido en forma de mantequilla de cacahuate entre los 4 y 11 meses, bajo la supervisión estricta de un profesional capacitado. El gluten se puede introducir entre los 4 y 12 meses de edad. Todos los niños deben recibir alimentos complementarios ricos en hierro, que incluyan productos a base de carne o alimentos fortificados con hierro. Deben evitarse los alimentos con aditivos de azúcar o sal. Las dietas veganas sólo deben usarse bajo una estricta vigilancia médica y supervisión dietética, para asegurarse de que el bebé reciba un suministro adecuada de vitamina B 12 , Vitamina D, hierro, zinc, ácido fólico, ácidos grasos poliinsaturados de cadena larga n-3, proteínas, y calcio.

Es probable que en un futuro se establezcan recomendaciones para aspectos específicos de la alimentación complementaria, basadas en resultados que tengan en cuenta las diferencias étnicas y poblacionales. Estas recomendaciones se hacen para los niños que viven en México, aunque pueden ser aplicables en toda Latinoamérica, y pretenden que el profesional de la salud, promueva una adecuada alimentación y una correcta progresión de la alimentación complementaria, con el fin de favorecer un adecuado crecimiento y desarrollo del lactante, pero a la vez, prevenir el desarrollo de diferentes noxas patológicas de tipo inmune y nutricional.

\section{REFERENCIAS}

1. World Health Organization. Complementary Feeding: Report of the Global Consultation and Summary of Guiding Principles. Geneva, Switzerland: World Health Organization; 2001. 
2. Gartner LM, Morton J, Lawrence RA, Naylor AJ, O'Hare $D$, Schanler RJ, et al. Breastfeeding and the use of human milk. Pediatrics. 2005;115:496-506.

3. Fewtrell M, Bronsky J, Campoy C, et al. Complementary Feeding: A Position Paper by the European Society for Paediatric Gastroenterology, Hepatology, and Nutrition (ESPGHAN) Committee on Nutrition. JPGN. 2017;64:119-132

4. OPS/OMS. La alimentación del lactante y del niño pequeño: capítulo modelo para libros de texto dirigidos a estudiantes de medicina y otras ciencias de la salud. Washington, D.C.: OPS 2010.

5. Romero-Velardea E, Villalpando-Carrión S, Pérez-Lizaur $A B$, et al. Consenso para las prácticas de alimentación complementaria en lactantes sanos. Bol Med Hosp Infant Mex. 2016;73:338-356.

6. Naylor AJ, Morrow A. Developmental Readiness of Normal Full Term Infants to Progress from Exclusive Breastfeeding to the Introduction of Complementary Foods: Reviews of the Relevant Literature Concerning Infant Immunologic, Gastrointestinal, Oral Motor and Maternal Reproductive and Lactational Development. Washington, DC: Wellstart International and the LINKAGES Project/Academy for Educational Development, 2001.

7. Ramírez-Mayans JA, García-Campos M, Montijo-Barrios E. Nutrición en el niño sano, Insitituto Nacional de Pediatría. México: 2007. p.36-43.

8. Northstone K, Emmett P, Nethersole F. The effect of age of introduction to lumpy solids on foods eaten and reported feeding difficulties at 6 and 15 months. J Hum Nutr Diet. 2001;14:43-54.

9. Grand RJ, Watkins JB, Torti FM. Development of the human gastrointestinal tract. Gastroenterology. 1976;70:790-810.

10. Kelly EJ, Newell SJ, Brownlee KG, Primrose JN, Dear PR.Gastric acid secretion in preterm infants. Early Hum Dev.1993;35:215-220.

11. McClean P, Weaver LT. Ontogeny of human pancreatic exocrine function. Arch Dis Child. 1993;68:62-65.

12. Kashtanova DA, Popenko AS, Tkacheva ON, Tyakht AB, Alexeev DG, Boytsov SA. Association between the gutmicrobiota and diet: Fetal life, early child hood, and furtherlife. Nutrition. 2016;32(6):620-7.

13. Ziegler EE, Fomon SJ. Fluid intake, renal solute load, and water balance in infancy. J Pediatr 1971;78:561-8.

14. Giovannini M, Riva E, Banderali G, Scaglioni S, Veehof SH, Sala $M$, et al. Feeding practices of infants through the first year of life in Italy. Acta Paediatr 2004; 93:492-7.

15. Koletzko B, Dokoupil K, Reitmayr S, Weimert-Harendza B, Keller E. Dietary fatin takes in infants and primary school children in Germany. Am J Clin Nutr 2000;72:1392-8.

16. Bolling K, Grant C, Hamlyn B, Thornton A. Infant Feeding Survey 2005. PL London: PN Thelnformation Centre, National Health Service; 2007.
17. Sievers E, Hellmeier W. Ausländische Neugeborene in Deutschland: Analysen zur Säuglingssterblichkeit. Z Geburt shilfe Neonatol. 2007; S1: 211-FV223.

18. González de Cossío T, Escobar-Zaragoza L, González-Castell D, Reyes-Vázquez $\mathrm{H}$, Rivera-Dommarco JA. Breastfeeding in Mexico was stable, on average, but deteriorated amongthe poor, whereas complementary feeding improved: results from the 1999to 2006 National Health and Nutrition Surveys. J Nutr. 2013;143(5):664-7.

19. Lutter CK.Growth and complementary feeding in the Americas. Nutr Metab Cardiovasc Dis. 2012 Oct;22(10):806-12.

20. Pantoja-Mendoza IY, Meléndez G, Guevara-Cruz M, Serralde-Zúñiga AE.Review of complementary feeding practices in Mexican children. Nutr Hosp. 2014 19;31(2):552-8.

21. Northstone K, Emmett P, Nethersole F. The effect of age of introduction to lumpy solids on foods eaten and reported feeding difficulties at 6 and 15 months. J Hum Nutr Diet. 2001;14:43-54.

22. Perdomo-Giraldi M, Durán FM. Alimentación complementaria en el lactante. Pediatr Integral. 2015;19(4):260-67.

23. Martínez-Ojinaga Nodal, E. "Gluten y lactancia materna": adiós a la ventana inmunológica”. Evid Pediatr. 2014;10:58.

24. OMS. Directriz: Administración de suplementos de vitamina $A$ a lactantes y niños 6-59 meses de edad. Ginebra, Organización Mundial de la Salud, 2011.

25. OMS. Guideline: Dailyiron supplementation in infants and children. Geneva: World Health Organization; 2016.

26. WHO/UNICEF. Jointstatement: iron supplementation of young children in regions where malaria transmission is intense and infectious disease highly prevalent. Geneva, World Health Organization, 2006.

27. WHO. Conclusions and recommendations of the WHO consultation on prevention and control of iron-deficiency anaemia in infants and young children in malaria-endemic areas. Geneva World Health Organization, 2006.

28. WHO/UNICEF Joint Statement. Reaching optimal iodine nutrition in pregnant and lactating women and young children. Geneva, World Health Organization, 2007.

29. Krebs NF, Miller LV, Hambidge KM. Zinc deficiency in infants and children: a review of its complex and synergistic interactions. Paediatr Int Child Health. 2014;34(4):279-88.

30. Pallás Alonso, CR. Vitamina D profiláctica. Recomendación. En Recomendaciones PrevInfad / PAPPS [en línea]. Agosto 2009. Disponible enhttp://www.aepap.org/previnfad/ rec_vitamina_d.htm

31. Prescott SL1, Smith P, Tang M, Palmer DJ, Sinn J, Huntley $\mathrm{SJ}$, et al. The importance of early complementary feeding in the development of oral tolerance: Concerns and controversies. Pediatr Allergy Immunol. 2008;19:375-80.

32. Akobeng AK, Ramanan AV, Buchan I, Heller RF. Effect of breast feeding on risk of coeliac disease: a systematic review and meta-analysis of observational studies. Arch Dis Child. 2006;91:39-43. 
and final recommendations. Pediatr Allergy Immunol. 2004;15:291-307.

42. Du Toit G, Roberts G, Sayre PH, Plaut M, Bahnson HT, Mitchell $\mathrm{H}$, et al. Identifying infants at high risk of peanut allergy: the Learning Early about Peanut Allergy (LEAP) screening study. J Allergy Clin Immunol 2013;131:135-43.

43. Perkin MR, Logan K, Tseng A, Raji B, Ayis S, Peacock J, et al. Randomized Trial of Introduction of Allergenic Foods in Breast-Fed Infants. N Engl J Med. 2016;374(18):173343.

44. Norris JM, Barriga K, Klingensmith G, Hoffmann M, Eisenbarth GS, Erlich HA, et al. Timing of initial cereal exposure in infancy and risk of isletautoimmunity. JAMA. n 2003;290:1713-20.

45. Owen CG, Martin RM, Whincup PH, Smith GD, Cook DG. Does breast-feeding influence risk of type 2 diabetes in laterlife? A quantitative analysis of published evidence. Am J n Cli Nutr. 2006;84:1043-54.

46. Burdette HL, Whitaker RC, Hall WC, Daniels SR. Breastfeeding, introduction of complementary foods, and adiposity $\mathrm{n}$ at $5 \mathrm{y}$ of age. Am J Clin Nutr. 2006;83:550-8.

47. Seach KA, Dharmage SC, Lowe AJ, Dixon JB. Delayed introduction of solid feeding reduces childover weight and obesity at 10 years. Int J Obes (Lond). 2010;34:1475-9.

48. Owen CG, Martin RM, Whincup PH, Smith GD, Cook DG. Effect of infant feeding on the risk of obesity a cross the life course: a quantitative review of published evidence. Paediatrics. 2005;115:1367-77.

49. Arana Cañedo-Argüelles C. Dietas vegetarianas. RevPediatr Aten Primaria. 2006;8:S119-131.

50. Moreno Villares JM, Galiano Segovia MJ, Dalmau Serra J. Alimentación complementaria dirigida por el bebé ("baby- ledweaning"). ¿Es una aproximación válida a la introducción de nuevos alimentos en el lactante? Acta Pediatr Esp. 2013; 71: 99-103.

51. Cameron SL, Heath AM, Taylor RW. How feasibleis babyledweaning as an approach to infant feeding? A review of theevidence. Nutrients. 2012;4:1575-609.

52. Cameron SL, Taylor RW, Heath AL. Development and pilot testing of Baby-Led Introduction to Solids-a version of Baby-Led Weaning modified to address concerns about iron deficiency, growth faltering and choking. BMC Pediatr. 2015; 26;15:99. DOI: 10.1186/s12887-015-0422-8 